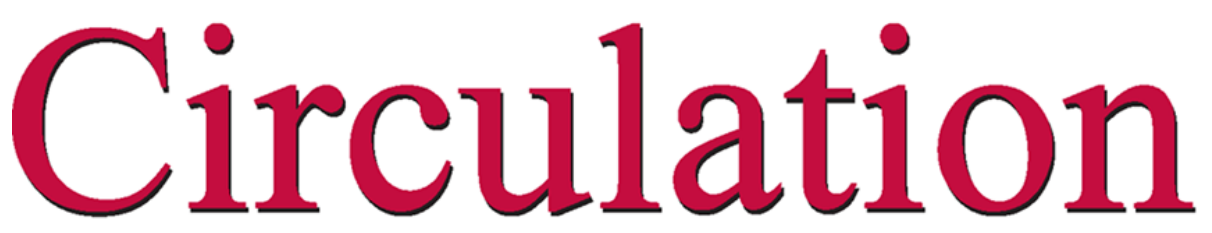

JOURNAL OF THE AMERICAN HEART ASSOCIATION
American Heart Association

Learn and Live

Association of Insulin Resistance, Hyperleptinemia, and Impaired Nitric Oxide

Release With In-Stent Restenosis in Patients Undergoing Coronary Stenting

PierMarco Piatti, Carlo Di Mario, Lucilla D. Monti, Gabriele Fragasso, Fabio Sgura, Andrea Caumo, Emanuela Setola, Pietro Lucotti, Elena Galluccio, Cristina Ronchi, Anna Origgi, Ivana Zavaroni, Alberto Margonato and Antonio Colombo

Circulation 2003, 108:2074-2081: originally published online October 6, 2003 doi: 10.1161/01.CIR.0000095272.67948.17

Circulation is published by the American Heart Association. 7272 Greenville Avenue, Dallas, TX 72514

Copyright @ 2003 American Heart Association. All rights reserved. Print ISSN: 0009-7322. Online ISSN: 1524-4539

The online version of this article, along with updated information and services, is located on the World Wide Web at: http://circ.ahajournals.org/content/108/17/2074

Subscriptions: Information about subscribing to Circulation is online at

http://circ.ahajournals.org//subscriptions/

Permissions: Permissions \& Rights Desk, Lippincott Williams \& Wilkins, a division of Wolters Kluwer Health, 351 West Camden Street, Baltimore, MD 21202-2436. Phone: 410-528-4050. Fax: 410-528-8550. E-mail:

journalpermissions@lww.com

Reprints: Information about reprints can be found online at http://www.lww.com/reprints 


\title{
Association of Insulin Resistance, Hyperleptinemia, and Impaired Nitric Oxide Release With In-Stent Restenosis in Patients Undergoing Coronary Stenting
}

\author{
PierMarco Piatti, MD; Carlo Di Mario, MD; Lucilla D. Monti, MD; Gabriele Fragasso, MD; \\ Fabio Sgura, MD; Andrea Caumo, MD; Emanuela Setola, MD; Pietro Lucotti, MD; \\ Elena Galluccio, PhD; Cristina Ronchi, PhD; Anna Origgi, MD; Ivana Zavaroni, MD; \\ Alberto Margonato, MD; Antonio Colombo, MD
}

Background — Previously undiagnosed diabetes, impaired glucose tolerance, and insulin resistance are common in patients with acute myocardial infarction and coronary heart disease (CHD) and might be involved in early restenosis after stent implantation. To evaluate whether markers of insulin resistance syndrome, including leptin, and endothelial dysfunction are related to increased rate of early restenosis, we studied nondiabetic patients with CHD after successful coronary stenting.

Methods and Results - Both patients with CHD undergoing coronary stenting (120 patients) and control subjects (58 patients) were submitted to an oral glucose tolerance test (OGTT). Fasting leptin levels and fasting and postglucose load insulin sensitivity were assessed. Endothelial function was measured by nitrite and nitrate release (NOx) during OGTT. More than 50\% of patients treated with stent implantation presented impaired glucose tolerance or type 2 diabetes, which was previously undiagnosed. These patients also had higher glucose, insulin, and leptin levels than control subjects. Among the stented patients, insulin and leptin levels were higher in patients with restenosis than in patients without restenosis. A significant increase in NOx levels was found during OGTT both in patients without restenosis and in control subjects. On the contrary, NOx profiles were blunted in patients with restenosis. At multiple regression analysis, only $\triangle$ AUC-NOx areas and insulin sensitivity index showed an independent correlation with the minimal lumen diameter at follow-up.

Conclusions-We demonstrated that insulin resistance and endothelial dysfunction are independent predictors of early restenosis after coronary stenting. (Circulation. 2003;108:2074-2081.)

Key Words: restenosis — diabetes mellitus — coronary disease @ metabolism $\square$ nitric oxide

$\mathrm{R}$ ecent serial intravascular ultrasound studies in nondiabetic patients showed that neointimal tissue proliferation after stent implantation was greater in patients with impaired glucose tolerance than in patients with normal glucose tolerance at follow-up and that the best predictor of restenosis was the sum of insulin levels after oral glucose tolerance test (OGTT). ${ }^{1}$ Another cause of restenosis might be a reduced synthesis of NO (NOx), because NOx has been demonstrated to decrease migration and proliferation of vascular smooth muscle cells to attenuate binding of inflammatory cells to the vascular wall, inhibit thrombosis by reducing platelet adhesion and aggregation, and maintain vascular relaxation. ${ }^{2-4}$

In addition, leptin, a hormone related to fat metabolism and insulin resistance (IR), has been recognized as an independent risk factor for coronary heart disease in a large cohort of the West of Scotland (WOSCOPS). ${ }^{5}$ Moreover, leptin has emerged as a metabolic hormone that contributes importantly to regulation of vascular biology, and it was reported that leptin modulates endothelial NO synthesis. ${ }^{6,7}$

The aim of this study was to evaluate the relationships between IR, leptin levels, and endothelial function, evaluated as NOx release during OGTT, and the degree of restenosis 6 months after successful coronary stenting in nondiabetic patients with coronary heart disease (CHD).

\section{Subjects}

We enrolled 120 consecutive patients (mean age, 59.0 \pm 1.4 years: mean body mass index $[\mathrm{BMI}], 25.7 \pm 0.7 \mathrm{~kg} / \mathrm{m}^{2}$ ) routinely submitted

Received February 18, 2003; de novo received June 2, 2003; revision received July 29, 2003; accepted July 29, 2003.

From the Cardiovascular and Metabolic Rehabilitation Unit, Rehabilitation and Functional Reeducation Division, and Laboratory L20, Core Lab, Diabetology, Endocrinology, Metabolic Disease Unit, IRCCS H. San Raffaele (P.P., L.D.M., E.S., P.L., E.G., C.R., A.O.); Catheterization Laboratories, IRCCS H. San Raffaele (C.D.M., F.S., A.C.); Clinical Cardiology Unit, Cardiothoracic and Vascular Department, IRCCS H. San Raffaele (G.F., A.M.), Milan; Nutrition and Metabolism Unit, Medicine Division, IRCCS H. San Raffaele (A.C.); and Department of Internal Medicine and Biochemical Science, Parma University (I.Z.), Parma, Italy.

Correspondence to PierMarco Piatti, MD, Cardiovascular and Metabolic Rehabilitation Unit, Medicine Division, Via Olgettina 60, 20132 Milano, Italy. E-mail piermarco.piatti@hsr.it

(C) 2003 American Heart Association, Inc.

Circulation is available at http://www.circulationaha.org 
TABLE 1. Clinical and Metabolic Characteristics of 69 Patients With CHD Submitted to Stenting Procedures and 58 Control Subjects (Mean \pm SD)

\begin{tabular}{|c|c|c|c|}
\hline & $\begin{array}{l}\text { Patients With } \\
\text { Restenosis } \\
(\mathrm{N}=30)\end{array}$ & $\begin{array}{l}\text { Patients Without } \\
\text { Restenosis } \\
(\mathrm{N}=39)\end{array}$ & $\begin{array}{l}\text { Control } \\
\text { Subjects } \\
(\mathrm{N}=58)\end{array}$ \\
\hline Age, y & $55.8 \pm 10.4$ & $58.7 \pm 10.0$ & $57.1 \pm 6.9$ \\
\hline Weight, kg & $78.3 \pm 15.9$ & $73.2 \pm 6.9$ & $73.7 \pm 13.7$ \\
\hline BMI, kg/m² & $27.1 \pm 4.4$ & $25.6 \pm 1.9$ & $26.8 \pm 3.8$ \\
\hline Waist/hip ratio & $0.96 \pm 0.11$ & $0.97 \pm 0.06$ & $0.95 \pm 0.08$ \\
\hline Systolic blood pressure, mm Hg & $130 \pm 16$ & $134 \pm 12$ & $127 \pm 15.2$ \\
\hline Diastolic blood pressure, $\mathrm{mm} \mathrm{Hg}$ & $81 \pm 6$ & $83 \pm 12$ & $80 \pm 8$ \\
\hline Glucose, mg/dL & $104.1 \pm 15.9$ & $98.0 \pm 19.4$ & $97.4 \pm 10.7$ \\
\hline Insulin, $\mu \mathrm{U} / \mathrm{mL}$ & $10.8 \pm 6.4^{\star} \dagger$ & $8.0 \pm 2.3$ & $6.8 \pm 3.5$ \\
\hline HOMA index & $2.81 \pm 1.99^{\star} \dagger$ & $1.93 \pm 0.59$ & $1.68 \pm 0.95$ \\
\hline $\mathrm{NOx}, \mu \mathrm{mol} / \mathrm{L}$ & $23.1 \pm 10.3 \dagger$ & $18.9 \pm 17.3$ & $14.7 \pm 13.9$ \\
\hline Leptin, ng/mL & $8.2 \pm 5.5^{\star} \dagger$ & $5.2 \pm 3.8$ & $5.0 \pm 4.6$ \\
\hline Cholesterol, mg/dL & $185 \pm 44$ & $193 \pm 50$ & $200 \pm 38$ \\
\hline HDL cholesterol, mg/dL & $50 \pm 16$ & $43 \pm 14$ & $48 \pm 1.2$ \\
\hline Triglyceride, mg/dL & $145 \pm 55$ & $142 \pm 75$ & $147 \pm 45$ \\
\hline Oral antiplatelet drugs, n (\%) & $30(100)$ & $39(100)$ & $\cdots$ \\
\hline$\beta$-blockers, $\mathrm{n}(\%)$ & $20(66)$ & $24(62)$ & $\cdots$ \\
\hline ACE inhibitors, n (\%) & $14(47)$ & $18(46)$ & $\cdots$ \\
\hline Statins, n (\%) & $19(64)$ & $25(64)$ & $\cdots$ \\
\hline Long-term treatment & 9 & 15 & $\cdots$ \\
\hline 6-month treatment & 10 & 10 & $\ldots$ \\
\hline
\end{tabular}

to angiographic control 6 months after successful coronary stenting. Previous diagnosis of type 2 diabetes mellitus was excluded. Among the whole group, the 46 patients with restenosis, defined as recurrence and then $50 \%$ diameter reduction in the segment treated, showed a minimal lumen diameter (MLD) at follow-up of $0.95 \pm 0.49$ versus $2.65 \pm 0.62 \mathrm{~mm}$ in the group without restenosis (74 patients). After a standard oral glucose test (75 g), 16 patients with restenosis and 35 patients without restenosis showed plasma glucose concentrations diagnostic for type 2 diabetes at 2 hours postload; 12 patients with restenosis and 14 patients without restenosis had an impaired glucose tolerance (IGT), whereas 18 patients with restenosis and 25 patients without restenosis demonstrated a normal glucose tolerance (NGT).

Because type 2 diabetes mellitus has well-known detrimental effects on insulin resistance and endothelial dysfunction, we chose to focus our attention on NGT or IGT CHD patients. To this aim, we evaluated 30 patients with restenosis and 39 patients without restenosis matched for age, gender, successful coronary stenting of a single coronary stenosis, no previous history of diabetes mellitus, normal fasting glucose, normal glycohemoglobin, cholesterol, HDL cholesterol and triglyceride levels, normal systolic and diastolic blood pressure levels, and similar antilipidemic and antihypertensive therapy. Their clinical and metabolic characteristics are depicted in Table 1.

A standard OGTT was also performed in 58 nondiabetic and non-CHD control subjects, matched with CHD patients for age, gender, weight, BMI, systolic and diastolic pressure, triglyceride, and HDL cholesterol (Table 1). All control subjects showed a normal response after the glucose challenge. All subjects gave informed consent to participate in the study, and the local ethics committee approved the protocol.

\section{Methods}

\section{Stent Implantation and Clinical and Angiographic Follow-Up}

Patients with CHD submitted to the procedure were treated with IV heparin and combined antiplatelet therapy, whereas IIb/IIIa inhibitors were used at the operator's discretion. Customized stents mounted on expandable balloon from Phitis Diamond Plus Stent were implanted. A minimal balloon inflation pressure of 14 atm was recommended.

After 6 months, patients were scheduled for control angiography. Other angiographic examinations performed before 6 months for recurrence of symptoms were used only if restenosis was present. Quantitative coronary angiography analysis was performed using a validated automated edge-detection program (CMS version 5.2, MEDIS). MLD, length of stenosis, and percentage diameter stenosis after 6 months were measured. In addition, the following parameters were assessed: acute gain, MLD after the procedure minus MLD before the procedure; late loss, MLD after the procedure minus MLD at follow-up; net gain, difference between acute gain and late loss; and restenosis, presence of $>50 \%$ stenosis at follow-up. Results of all the parameters before and after stent implantation and at 6-month angiographic follow-up are reported in Table 2.

\section{OGTT and Measurement of Insulin Sensitivity}

At 8:00 AM, after a 10- to 12-hour overnight fast, all subjects received a 75-g OGTT. Arterialized blood samples, taken without tourniquet, were withdrawn at $0,30,60$, and 120 minutes for measurement of plasma glucose, insulin, and NOx concentrations.

In particular, for NOx evaluation, in a previous study we demonstrated that arterialized NOx levels are a reliable index of forearm arterial levels, because there was a highly significant correlation 
TABLE 2. Quantitative Angiographic Evaluation in 69 Patients at 6-Month Angiographic Follow-Up (Mean \pm SD)

\begin{tabular}{lccc}
\hline & $\begin{array}{c}\text { Patients With } \\
\text { Restenosis } \\
(\mathrm{N}=30)\end{array}$ & $\begin{array}{c}\text { Patients Without } \\
\text { Restenosis } \\
(\mathrm{N}=39)\end{array}$ & $\begin{array}{c}P \\
\text { Values }\end{array}$ \\
\hline Reference diameter, mm & & & \\
$\quad$ Before & $2.91 \pm 0.55$ & $2.99 \pm 0.69$ & 0.57 \\
$\quad$ After & $3.06 \pm 0.49$ & $3.22 \pm 0.62$ & 0.25 \\
$\quad$ Follow-up & $2.73 \pm 0.55$ & $2.99 \pm 0.62$ & 0.10 \\
Minimal luminal diameter, mm & & & \\
$\quad$ Before & $0.78 \pm 0.55$ & $0.77 \pm 0.50$ & 0.96 \\
After & $2.65 \pm 0.60$ & $2.87 \pm 0.62$ & 0.14 \\
Follow-up & $0.95 \pm 0.49$ & $2.55 \pm 0.62$ & 0.0001 \\
Diameter stenosis, \% & & & \\
$\quad$ Before & $72.6 \pm 16.4$ & $73.1 \pm 15.0$ & 0.88 \\
After & $14.1 \pm 11.5$ & $9.7 \pm 15.6$ & 0.20 \\
Follow-up & $64.2 \pm 16.4$ & $16.5 \pm 12.5$ & 0.0001 \\
Length stenosis, mm & & & \\
Before & $10.1 \pm 8.2$ & $9.8 \pm 7.5$ & 0.87 \\
Follow-up & $14.2 \pm 14.7$ & $5.4 \pm 3.7$ & 0.0008 \\
Acute gain, mm & $1.84 \pm 0.60$ & $2.11 \pm 0.69$ & 0.10 \\
Late loss, mm & $1.70 \pm 0.66$ & $0.36 \pm 0.56$ & 0.0001 \\
Net gain (mm) & $0.14 \pm 0.60$ & $1.75 \pm 0.69$ & 0.0001 \\
\hline
\end{tabular}

between arterial and arterialized NOx levels $(r=0.90, P<0.001$; slope, $0.93 \pm 0.11 ; P<0.16$ versus a slope of 1.0 ; intercept, $1.32 \pm 2.86 ; P<0.11$ versus an intercept of 0$).{ }^{8}$

In addition, in a pilot study, arterialized blood samples were taken every 10 minutes over 1 hour in 7 fasting subjects. NOx levels remained stable during this period, with intrasubject coefficient of variation $(\mathrm{CV})$ values ranging from $3.7 \%$ to $8.5 \%$ (mean $\mathrm{CV}$, $5.8 \pm 1.8 \%$ ), suggesting that NOx levels remain constant over time in fasting subjects not submitted to an OGTT. At time 0 , blood samples were also taken for measurement of leptin, glycohemoglobin, triglycerides, HDL cholesterol, and total cholesterol.

\section{Assays}

Blood glucose, glycohemoglobin, triglycerides, HDL cholesterol, and total cholesterol were measured with spectrophotometric methods adapted to Cobas Fara II using commercial kits (Unimate, Roche). Serum insulin levels were assayed with a microparticle enzyme immunoassay (IMX; Abbott Laboratories).

NOx levels were evaluated through the measurement of metabolic end products, ie, nitrite and nitrate, using enzymatic catalysis coupled with Griess reaction, as reported by Verdon et al, ${ }^{9}$ with an intra-assay $\mathrm{CV}$ of $4.1 \%$ and an interassay $\mathrm{CV}$ of $9.7 \%$. Leptin levels were measured with an ELISA kit (Linco Research, Inc).

\section{Measurement of Insulin Sensitivity and Insulin Secretion}

We used 2 different methods to assess insulin sensitivity in the 3 study groups. One is based on the baseline glucose and insulin data, whereas the other exploits the dynamic glucose and insulin data measured during the OGTT. We used the fasting glucose and insulin values to calculate the homeostasis model assessment index of IR (HOMA-IR) according to the following formula: HOMA$\mathrm{IR}=[$ baseline insulin concentration $(\mu \mathrm{U} / \mathrm{mL}) \cdot$ baseline glucose concentration $(\mathrm{mmol} / \mathrm{L}) / 22.5] .^{10}$

We used the glucose and insulin determinations during the OGTT to calculate an index of insulin sensitivity, defined as SI (oral) $\left(10^{-4} \mathrm{dL} \mathrm{kg}^{-1} \mathrm{~min}^{-1} / \mu \mathrm{U} \mathrm{mL}^{-1}\right)$. The calculation of SI (oral) hinges on the intuitive notion that the glucose and insulin excursions during the OGTT reflect the degree of IR of the subject receiving the test. For instance, a large glucose excursion, accompanied by a large insulin excursion, indicates the presence of IR. This notion has been put on firm theoretical grounds using a mathematical model of the glucose insulin system (the so-called minimal model). ${ }^{11}$ The model allows derivation of a formula for insulin sensitivity based on the area under the curve (AUC) of glucose and insulin concentrations during the OGTT. ${ }^{12,13}$

Insulin secretion was evaluated in the 3 study groups by calculating the AUC of the incremental (above basal) insulin excursion during the OGTT ( $\triangle$ AUC insulin area). All AUCs were calculated using the trapezoidal method.

In addition, to obtain an objective characterization of the relationship between insulin sensitivity and insulin secretion, we performed a hyperbolic regression by fitting the experimental data to the following hyperbolic function: $\Delta$ AUC insulin area $=\mathrm{p} 1+\mathrm{p} 2 / \mathrm{SI}$ oral The unknown parameters $\mathrm{p} 1$ and $\mathrm{p} 2$ were estimated using the Nonlinear Curve Fitting Module of the JMP statistical software (SAS Institute, Inc).

\section{Statistical Analysis}

All values are expressed as mean $\pm \mathrm{SD}$ at each time interval. Comparisons among groups were performed using 1-way ANOVA followed by the Scheffé $\mathrm{F}$ test when appropriate. A 2-tailed $P$ level of less than 0.05 was considered statistically significant. Triglyceride levels were logarithmically transformed to correct for skewness and subsequently backtransformed to their natural units for presentation in the tables. Simple and multiple regression analyses was performed with MLD at follow-up as the dependent variable and all other parameters as independent variables.

\section{Results}

In the fasting state, insulin, HOMA index (marker of insulin resistance), NOx, and leptin levels were significantly higher in patients treated with stent implantation (with or without restenosis) than in control subjects, whereas glucose levels were similar in the 3 groups. Among the patients who underwent stent implantation, patients with restenosis showed higher insulin and HOMA levels than patients without reste- 


\begin{tabular}{|c|c|c|c|}
\hline & $\begin{array}{l}\text { Patients With } \\
\text { Restenosis } \\
(\mathrm{N}=30)\end{array}$ & $\begin{array}{l}\text { Patients Without } \\
\text { Restenosis } \\
(\mathrm{N}=39)\end{array}$ & $\begin{array}{l}\text { Control } \\
\text { Subjects } \\
(\mathrm{N}=58)\end{array}$ \\
\hline \multicolumn{4}{|c|}{ Glucose, mg/dL } \\
\hline 0 & $104.1 \pm 15.9$ & $98.0 \pm 19.4$ & $97.4 \pm 10.7$ \\
\hline 30 & $172.4 \pm 33.6^{\star}$ & $168.5 \pm 34.2 \dagger$ & $118.3 \pm 21.8$ \\
\hline 60 & $194.3 \pm 49.1^{*}$ & $197.7 \pm 46.6 \dagger$ & $139.2 \pm 36.6$ \\
\hline 120 & $148.4 \pm 48.4^{\star}$ & $151.2 \pm 49.6 \dagger$ & $98.8 \pm 20.1$ \\
\hline \multicolumn{4}{|c|}{ Insulin, $\mu \mathrm{U} / \mathrm{mL}$} \\
\hline 0 & $10.8 \pm 6.4^{*} \ddagger$ & $8.0 \pm 2.3$ & $6.8 \pm 3.5$ \\
\hline 30 & $71.2 \pm 37.6^{\star} \ddagger$ & $52.3 \pm 32.3 \dagger$ & $37.0 \pm 20.0$ \\
\hline 60 & $100.1 \pm 73.0^{\star}$ & $75.0 \pm 32.3$ & $67.5 \pm 38.8$ \\
\hline 120 & $80.6 \pm 75.6^{\star} \ddagger$ & $51.2 \pm 34.6$ & $31.9 \pm 24.1$ \\
\hline \multicolumn{4}{|c|}{$\mathrm{NOX}, \mu \mathrm{mol} / \mathrm{L}$} \\
\hline 0 & $23.1 \pm 10.3^{*}$ & $18.9 \pm 17.3$ & $14.7 \pm 13.9$ \\
\hline 30 & $20.2 \pm 12.3$ & $23.3 \pm 17.4$ & $16.2 \pm 9.8$ \\
\hline 60 & $19.7 \pm 11.6$ & $21.6 \pm 15.5$ & $17.8 \pm 9.6$ \\
\hline 120 & $17.5 \pm 12.2$ & $17.0 \pm 13.2$ & $14.3 \pm 12.3$ \\
\hline
\end{tabular}

nosis, suggesting a state of fasting IR in the presence of increased leptin levels (Table 1).

Table 3 shows the pattern of plasma glucose, insulin, and NOx levels during OGTT in patients with and without restenosis and in control subjects, whereas Figure 1 shows SI oral values, insulin incremental areas, and NOx incremental areas during OGTT. Patients with or without restenosis showed higher glucose levels than control subjects, but the profile was identical in the 2 groups (Table 3, top). Both groups of CHD patients with or without restenosis were markedly more insulin resistant than control subjects, as demonstrated by the low SI oral, even if patients with restenosis were significantly more insulin resistant than patients without restenosis (Figure 1, top).

Interestingly, even if both CHD patients groups were hyperinsulinemic after the glucose load, insulin levels were markedly higher in patients with restenosis than in patients without restenosis (Table 3 , middle). This result was also displayed by the evaluation of insulin incremental areas (Figure 1, middle) that was increased by approximately $80 \%$ and $30 \%$ in patients with and without restenosis, respectively, compared with control subjects, suggesting that CHD patients with restenosis had the highest insulin secretion to maintain similar glucose pattern.

NOx profiles were blunted in patients with restenosis, whereas a significant increase in NOx levels was demonstrated after OGTT both in patients without restenosis and in control subjects (Table 3 , bottom). A negative $\triangle$ AUC-NOx area was observed in patients with restenosis, whereas a similar positive increment was found in patients without restenosis and in control subjects (Figure 1, bottom).
Taking all CHD patients together, at simple regression analysis, MLD at follow-up significantly correlated with SI oral ( $r=0.39, P<0.001)$, HOMA $(r=0.23, P<0.05)$, leptin levels $(r=0.26 ; P<0.03)$, and $\Delta$ AUC-NOx areas $(r=0.40, P<0.0006)$. At multiple regression analysis, in which all of the clinical and metabolic variables associated with the IR syndrome were included, only $\triangle$ AUC-NOx areas $(P=0.0079)$ and insulin sensitivity index (SI oral; $P=0.0207$ ) remained independently correlated with MLD at follow-up (Table 4).

To rule out the influence of endothelial dysfunction on restenosis independently of the role of hyperinsulinemia, we analyzed a subgroup of patients (22 patients with restenosis and 22 patients without restenosis) matched for insulin sensitivity (SI oral), insulin secretion during OGTT, and all other metabolic variables (Table 5). Also in this selected matched subgroup, leptin levels were higher and the $\triangle \mathrm{AUC}$ NOx was significantly lower in patients with restenosis compared with patients without restenosis.

\section{Discussion}

Restenosis constitutes an important limitation after stent implantation, but its pathogenesis is not yet fully understood. The results of the present study strongly suggest that a lack of NOx release after OGTT, increased leptin levels, hyperinsulinemia, and IR are important predictors of restenosis after coronary stenting in CHD patients with normal fasting glucose and glycated hemoglobin levels.

\section{Influence of NOx on Restenosis After Coronary Stenting}

In our opinion, the most striking result of the present study is that patients with $\mathrm{CHD}$ and restenosis have an important 

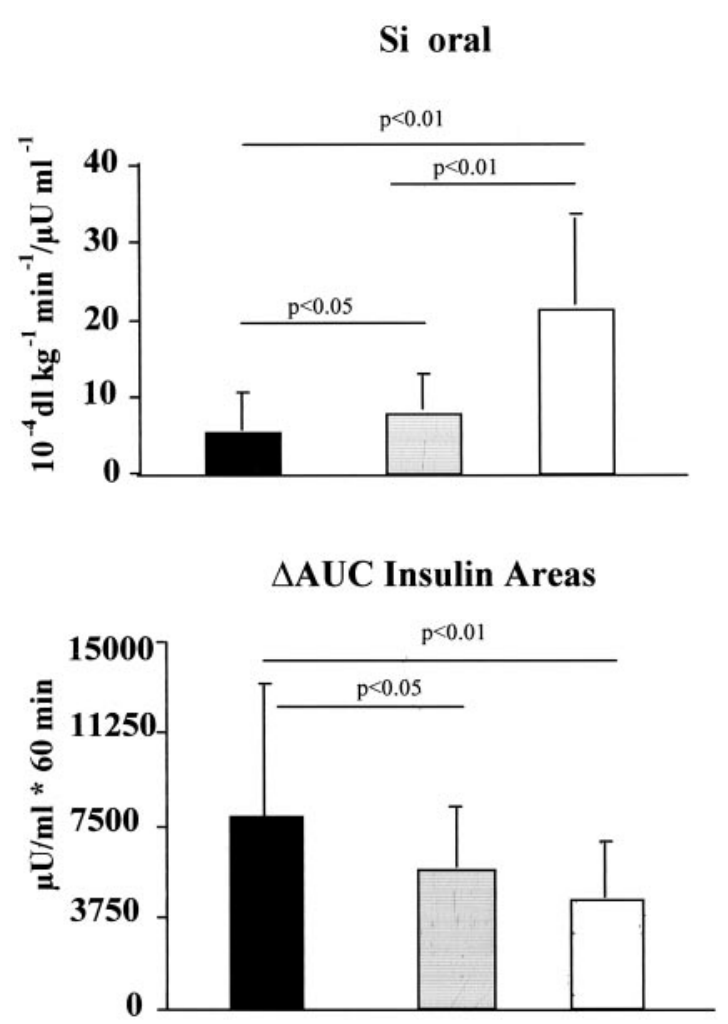

$\triangle A U C$ NOx Areas

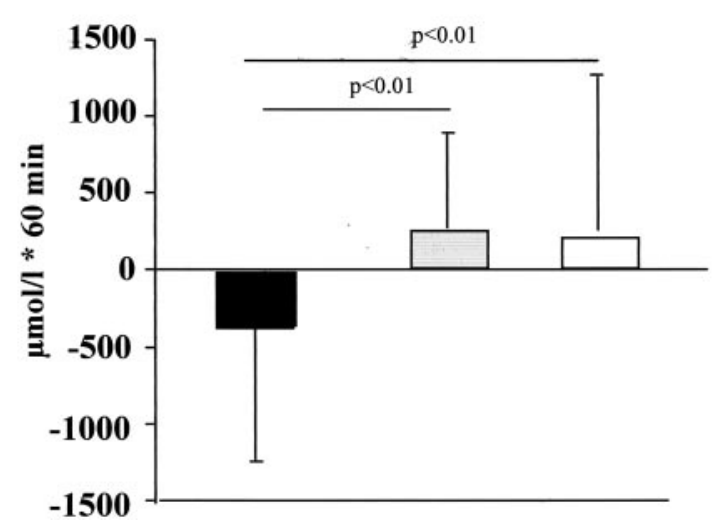

Figure 1. SI oral index (top), $\triangle A U C$ insulin areas (middle), and $\triangle A U C N O x$ areas (bottom) after OGTT (mean $\pm S D$ ). Black histograms represent patients with restenosis $(n=30)$; gray histograms, patients without restenosis $(n=39)$; and white histograms, control subjects $(n=58)$.

impairment of endothelial function, as suggested by increased fasting NOx levels and by the lack of NOx release during OGTT.

The increase in fasting NOx levels has been already reported in insulin-resistant subjects, ${ }^{14-16}$ and recently our group demonstrated that not only type 2 diabetic patients but also control subjects carrying 2 single nucleotide variants of endothelial NO synthase gene (E298D and IVS18+27A/C) had increased fasting NOx levels in the presence of IR, suggesting a common trait unifying IR syndrome and cardiovascular disease. ${ }^{17}$

The impairment of NOx release during OGTT in patients with restenosis was never, to our knowledge, previously
TABLE 4. Multiple Regression Analysis With Minimal Lumen Diameter at 6-Month Follow-Up After Stenting as the Dependent Variable $(r=0.577 ; P<0.04)$

\begin{tabular}{lccc}
\hline & & & $P$ \\
& $\beta$ Coefficient & F Ratio & Values \\
\hline$\Delta$-AUC NOx & 0.001 & 7.651 & 0.0079 \\
SI oral index & 0.094 & 5.707 & 0.0207 \\
Leptin & -0.06 & 1.073 & 0.305 \\
HOMA index & 0.034 & 0.053 & 0.819 \\
Waist/hip ratio & 2.07 & 0.614 & 0.437 \\
BMI & -0.031 & 0.249 & 0.619 \\
Triglycerides & -0.005 & 2.041 & 0.159 \\
Systolic blood pressure & -0.012 & 0.548 & 0.463 \\
Diastolic blood pressure & 0.020 & 0.659 & 0.421 \\
Age & 0.004 & 0.038 & 0.845 \\
Reference diameter before stenting & -0.030 & 0.008 & 0.928 \\
Stenosis length before stenting & 0.032 & 1.207 & 0.277 \\
\hline
\end{tabular}

demonstrated. This finding supports previous data in which restenosis was related to impaired NO production by the damaged endothelium. ${ }^{18}$ Furthermore, Wu et al ${ }^{19}$ showed that patients with in-stent restenosis 6 months after coronary stenting had impaired NO-dependent endothelial vasodilation compared with patients without restenosis.

Even if the biological explanation for decreased NOx levels during OGTT is difficult to explain, some hypotheses can be put forward. Patients with restenosis might have a greater increase in circulating vasoconstrictor agents, like endothelin-1, because endothelin-1 significantly inhibits NOx release by vascular smooth muscle cells after different stimuli. ${ }^{20}$ Our group has previously suggested that a decrease of endothelin-1 levels, induced by L-arginine infusion, was able to restore insulin-induced NOx release in subjects with cardiovascular syndrome $\mathrm{X}^{21}$

A negative correlation between leptin levels and $\triangle$ AUCNOx ( $r=-0.28 ; P<0.04$; data not shown) was demonstrated and might support previous data by Cooke et al, ${ }^{22}$ who postulated that the long-term consequence of hyperleptinemia is a reduction of NO synthesis attributable to the increased oxidative stress in endothelial cells. Still, the understanding of the molecular mechanisms that determine the impairment of NOx release in patients with restenosis is highly speculative and was beyond the scope of the present study. To solve this important issue, additional investigations are needed.

A limitation of our study could be that we measured plasma NOx concentrations from arterialized samples. It has been previously demonstrated that plasma NOx may not provide an accurate estimate of total NOx in blood because of different $\mathrm{CO}_{2} /$ bicarbonate concentrations in venous samples. ${ }^{23}$ However, we previously demonstrated a close relationship between arterialized and arterial samples (as reported in Methods) and demonstrated a very low arterialized $\mathrm{CO}_{2}$ variability over time $(\mathrm{CV}, 2.0 \pm 0.3 \%) .{ }^{8}$ Thus, we are quite confident that our results, suggesting a defect of NOx release during OGTT in patients with restenosis, are correct. 
TABLE 5. Clinical and Metabolic Characteristics of 22 Patients With Restenosis Matched for Insulin Sensitivity and Secretion With 22 Patients Without Restenosis (Mean \pm SD)

\begin{tabular}{|c|c|c|c|}
\hline & $\begin{array}{l}\text { Patients With } \\
\text { Restenosis } \\
(\mathrm{N}=22)\end{array}$ & $\begin{array}{l}\text { Patients Without } \\
\text { Restenosis } \\
(\mathrm{N}=22)\end{array}$ & $P$ \\
\hline Age, y & $54.9 \pm 10.3$ & $57.6 \pm 9.9$ & NS \\
\hline Weight, kg & $75.1 \pm 8.9$ & $73.0 \pm 7.0$ & NS \\
\hline $\mathrm{BMI}, \mathrm{kg} / \mathrm{m}^{2}$ & $26.1 \pm 2.8$ & $25.4 \pm 1.9$ & NS \\
\hline Waist/hip ratio & $0.95 \pm 0.09$ & $0.96 \pm 0.05$ & NS \\
\hline Systolic blood pressure, mm Hg & $132 \pm 19$ & $133 \pm 14$ & NS \\
\hline Diastolic blood pressure, $\mathrm{mm} \mathrm{Hg}$ & $81 \pm 9$ & $82 \pm 9$ & NS \\
\hline Glucose, mg/dL & $100 \pm 9$ & $97 \pm 14$ & NS \\
\hline Insulin, $\mu \mathrm{U} / \mathrm{mL}$ & $8.8 \pm 3.3$ & $8.2 \pm 2.3$ & NS \\
\hline HOMA index & $2.2 \pm 0.9$ & $2.0 \pm 0.5$ & NS \\
\hline NOx ( $\mu \mathrm{mol} / \mathrm{L})$ & $24.1 \pm 11.3$ & $21.4 \pm 21.5$ & NS \\
\hline $\mathrm{HbA1c}, \%$ & $5.6 \pm 0.5$ & $5.5 \pm 4.2$ & NS \\
\hline Cholesterol, mg/dL & $187 \pm 47$ & $191 \pm 38$ & NS \\
\hline HDL cholesterol, mg/dL & $48 \pm 24$ & $44 \pm 12$ & NS \\
\hline Triglyceride, mg/dL & $141 \pm 42$ & $138 \pm 61$ & NS \\
\hline SI oral index, $10^{-4} \mathrm{dL} \mathrm{kg}^{-1} \mathrm{~min}^{-1} / \mu \mathrm{U} \mathrm{mL} \mathrm{mL}^{-1}$ & $7.6 \pm 5.2$ & $6.2 \pm 2.4$ & NS \\
\hline$\Delta$ AUC insulin area, $\mu \mathrm{U} / \mathrm{mL}^{\star} 60 \mathrm{~min}$ & $5944 \pm 2293$ & $6222 \pm 2162$ & NS \\
\hline$\Delta$ AUC NOx area, $\mu \mathrm{mol} / \mathrm{L}^{*} 60 \mathrm{~min}$ & $-445 \pm 741$ & $184 \pm 769$ & 0.01 \\
\hline Leptin, ng/mL & $7.4 \pm 5.6$ & $4.6 \pm 2.4$ & 0.05 \\
\hline
\end{tabular}

\section{Influence of Increased Leptin Levels on Restenosis} After Coronary Stenting

Another interesting result of the present study is the fact that increased leptin levels were present in patients with restenosis after stenting whereas superimposable results were demonstrated in patients without restenosis and in control subjects. Our data seem to reinforce the role for leptin as an index of chronic inflammation, participating in the atherogenic process. $^{24}$ After the first demonstration in WOSCOPS ${ }^{5}$ of a role of leptin as an independent risk factor for coronary heart disease, recent studies have confirmed the role of leptin in cardiovascular and cerebrovascular disease. . $^{25,26}$

It is well-known that other parameters, such as C-reactive protein (CRP), are predictive of restenosis. In fact, recently the IMPRESS Study ${ }^{27}$ showed that high CRP levels 72 hours after successful coronary stenting is predictive of a worse prognosis at 12 months, probably suggesting an additional activation of the inflammatory process within the plaque itself and as a response to injury during coronary stenting. Moreover, CRP level at 48 hours after stent implantation in the carotid arteries was associated with a significantly higher 6-month restenosis. ${ }^{28}$ However, we could not derive data from this important parameter, because we did not have samples on the initial admission to the hospital or on the days after stent implantation.

\section{Influence of Insulin Resistance on Restenosis After Coronary Stenting}

Another important point is that patients with CHD with or without restenosis are markedly insulin resistant compared with control subjects, showing that patients with restenosis have the highest degree of IR. IR is a state in which peripheral tissues have decreased sensitivity to insulin, leading to increased circulating insulin levels to maintain euglycemia. In favor of a relationship between hyperinsulinemia and coronary restenosis after stenting, Takagi et $\mathrm{al}^{29}$ have shown that neointimal index measured 6 months after coronary stenting correlated with fasting and postglucose load insulin levels.

The concept that IR, even at the myocardial level, can precede the onset of overt diabetes by many years has been recently shown by Iozzo et al. ${ }^{30}$ The authors in this elegant study demonstrated that cardiovascular disease is accompanied by a generalized state of IR, involving also the normally contracting myocardium. In fact, in type 2 diabetic patients without cardiovascular disease, they found a severe myocardial IR, because insulin-mediated glucose uptake was reduced by $41 \%$ and a significant correlation $(r=0.38 ; P<0.02)$ was found between myocardial glucose uptake and the ejection fraction. Moreover, they suggested that IR, at the level of the myocardium, may precede and possibly cause the development of cardiovascular disease.

In keeping with abundant evidence in the literature and as reviewed by Kahn, ${ }^{31}$ insulin secretion is tightly linked to insulin sensitivity, and, given their interdependence, these variables should be considered in tandem. The relationship between insulin sensitivity and insulin secretion in human subjects with normal glucose tolerance demonstrates a hyperbolic shape, as represented in Figure 2 by the continuous line derived on data from our 58 control subjects. The nature of this relationship is such that, for any difference in insulin sensitivity, a corresponding reciprocal difference occurs in insulin response. The 2 mean values of patients with and 


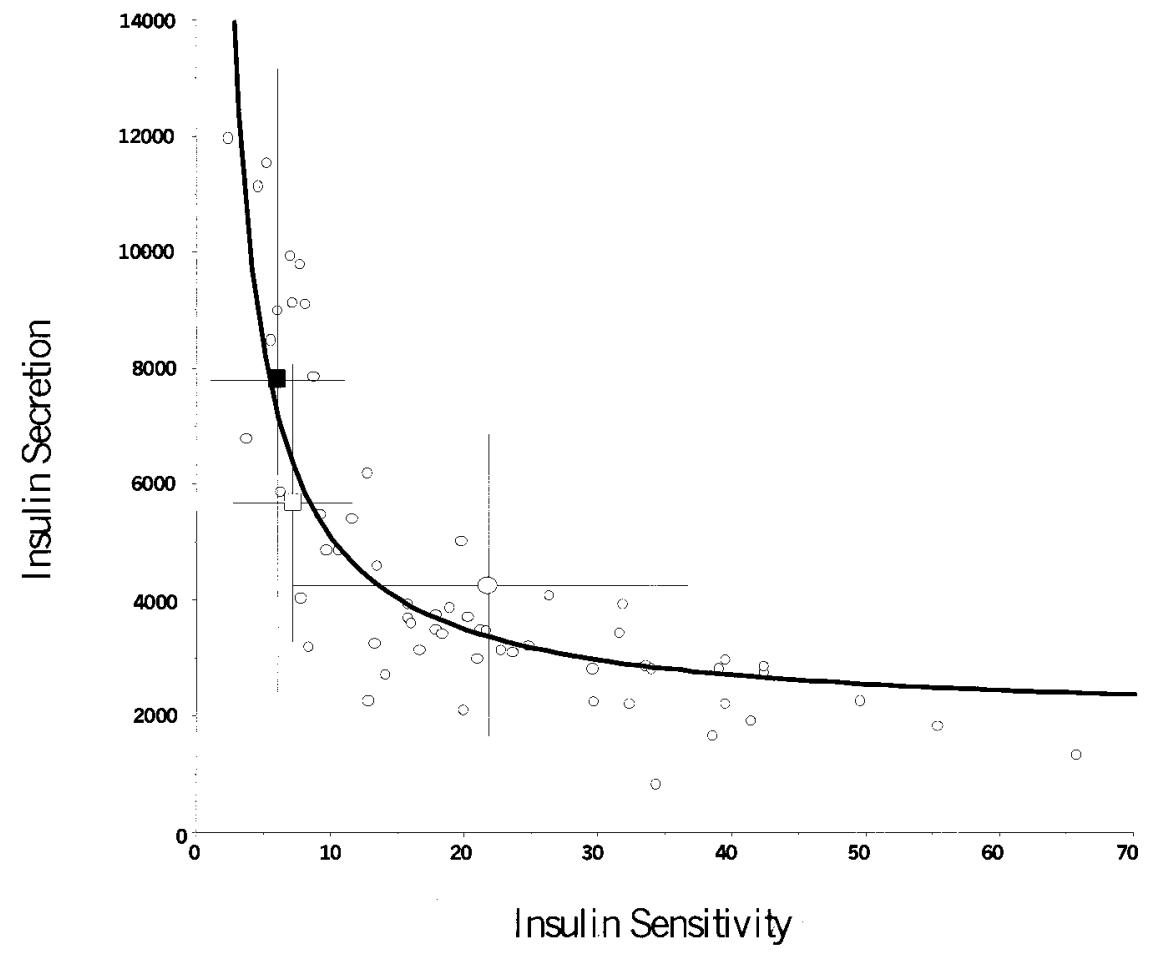

Figure 2. Reciprocal relationship between estimates of insulin sensitivity and insulin secretion, both obtained from the OGTT. The $x$ axis reports insulin sensitivity (SI oral) $\left(10^{-4} \mathrm{dL} \mathrm{kg}^{-1} \mathrm{~min}^{-1} / \mu \mathrm{U}\right.$ $\mathrm{mL}^{-1}$ ) levels, whereas the $y$ axis reports $\triangle \mathrm{AUC}$ insulin areas $\left(\mu \mathrm{U} / \mathrm{mL}^{*} 60\right.$ minutes), indicative of insulin secretion. Small white dots are individual values of the 2 variables found in healthy subjects, whereas the large white dot represents their mean value $( \pm S D$ for both variables). The solid line is the hyperbolic function (see Methods) fitting the relationship between insulin sensitivity and insulin secretion in 58 control subjects. The black square and the white square represent the mean values $( \pm S D)$ found in patients with restenosis $(n=30)$ and without restenosis $(n=39)$, respectively. without restenosis are both located in a steep segment of the hyperbolic curve, where little variations in insulin sensitivity (SI oral) induce large variations in insulin secretion ( $\triangle \mathrm{AUC}$ insulin area) during OGTT. Compared with patients without restenosis, patients with restenosis show a small reduction in insulin sensitivity but a large compensatory elevation in insulin response during OGTT, probably reflecting their inability to use insulin more efficiently. Thus, we can say that glucose tolerance remains constant in these patients because insulin sensitivity is matched by reciprocal changes in insulin secretion. Because the hyperbolic relationship between insulin sensitivity and insulin secretion has been described to act as a potential new tool to predict individuals at a high risk of developing diabetes, ${ }^{32}$ in our opinion, the hypothesis that improving insulin sensitivity might reduce the incidence of restenosis should be tested in a prospective trial.

\section{Clinical Implications}

Our results indicate that more than $50 \%$ of patients submitted to coronary stenting for ischemic heart disease present abnormal glucose levels after OGTT. Previous studies have shown that impaired glucose tolerance not only runs the risk of developing overt diabetes and its associated microvascular complications but also has an increased risk of cardiovascular morbidity and mortality compared with healthy glucosetolerant patients. ${ }^{33}$ Therefore, early detection of impaired glucose tolerance would permit initiation of secondary preventive treatment measures in such patients.

Our findings, according with recent data for myocardial infarction, ${ }^{34}$ suggest the utility to perform an OGTT, a quick, inexpensive, and easy test, to recognize high-risk individuals submitted to coronary stenting for ischemic heart disease at the time of admission. The limited availability of stents eluting antiproliferative drugs, effective in restenosis preven- tion, suggests that these expensive prostheses should be selectively implanted in this high-risk group.

\section{Conclusions}

In conclusion, the present study suggests that both insulin resistance and endothelial dysfunction are independent predictors of restenosis after coronary stenting. Evaluation of glucose tolerance, insulin secretion, and NOx release after a standard OGTT is an important tool in the attempt to recognize subjects at risk of early restenosis among nondiabetic patients undergoing percutaneous coronary revascularization. Furthermore, the isolated detections of insulin resistance and postglucose load hyperinsulinemia, although an important risk factor for $\mathrm{CHD}$, are poor predictors of restenosis after coronary stenting but are highly predictive if associated with increased leptin levels and the loss of NOx release during OGTT.

\section{Acknowledgments}

This work was supported in part by a grant from the Ministry of Health (ICS030.6/RF0049). The authors are grateful to Emilia Paola Sandoli and Sabrina Costa for their excellent technical assistance. They thank the Nurse Staff of the Clinical Cardiology Unit for their cooperation.

\section{References}

1. Takagi T, Akasaka T, Yamamuro A, et al. Impact of insulin resistance on neointimal tissue proliferation after coronary stent implantation: intravascular ultrasound studies. J Diabetes Complications. 2002;16:50-55.

2. Lefroy DC, Crake T, Uren NG, et al. Effects of inhibition of nitric oxide synthesis on epicardial coronary artery caliber and coronary blood flow in humans. Circulation. 1993;88:43-54.

3. Yao S-H, Ober JC, Krishnaswami A, et al. Endogenous nitric oxide protects against platelet aggregation and cyclic flow variations in stenosed and endothelium-injured arteries. Circulation. 1992;86: 1302-1309. 
4. Kubes P, Suzuki M, Granger DN. Nitric oxide: an endogenous modulator of leukocyte adhesion. Proc Natl Acad Sci U S A. 1991;83:1774-1777.

5. Wallace AM, Mc Mahon AD, Packard CJ, et al. Plasma leptin and the risk of cardiovascular disease in the West of Scotland Coronary Prevention Study (WOSCOPS). Circulation. 2001;104:3052-3056.

6. Lembo G, Vecchione C, Fratta L, et al. Leptin induced direct vasodilation through distinct endothelial mechanisms. Diabetes. 2000;49:293-297.

7. Vecchione C, Maffei A, Colella S, et al. Leptin effect on endothelial nitric oxide is mediated through Akt-endothelial nitric oxide synthase phosphorylation pathway. Diabetes. 2002;51:168-173.

8. Piatti P, Fragasso G, Monti LD, et al. Endothelial and metabolic characteristics of patients with angina and angiographically normal coronary arteries: comparison with subjects with insulin resistance syndrome and normal controls. J Am Coll Cardiol. 1999;34:1452-1460.

9. Verdon CP, Burto BA, Prior RL. Sample pretreatment with nitrate reductase and glucose-6-phosphate dehydrogenase quantitatively reduces nitrate while avoiding interference by NADP + ; when the Griess reaction is used to assay for nitrite. Anal Biochem. 1995;224:502-508.

10. Matthews DR, Hosker JP, Rudenski AS, et al. Homeostasis model assessment: insulin resistance and beta-cell function from fasting plasma glucose and insulin concentrations in man. Diabetologia 1985;28:412-419.

11. Bergman RN. Lilly lecture 1989 . Toward physiological understanding of glucose tolerance: minimal-model approach. Diabetes. 1989;38: 1512-1527.

12. Caumo A, Bergman RN, Cobelli C. Insulin sensitivity from meal tolerance tests in normal subjects: a minimal model index. J Clin Endocrinol Metab. 2000;85:4396-4402.

13. Breda E, Cavaghan MK, Toffolo G, et al. Oral glucose tolerance test minimal model indexes of beta-cell function and insulin sensitivity. Diabetes. 2001;50:150-158.

14. Piatti PM, Monti LD, Zavaroni I, et al. Alteration in nitric oxide/ cyclic-GMP pathway in nondiabetic siblings of patients with type 2 diabetes. J Clin Endocrinol Metab 2000; 85;2416-2420.

15. Zavaroni I, Piatti PM, Monti LD, et al. Plasma nitric oxide concentrations are elevated in insulin-resistant healthy subjects. Metabolism. 2000;49: 959-961.

16. Balletshofer BM, Rittig K, Enderle MD, et al. Endothelial dysfunction is detectable in young normotensive first-degree relatives of subjects with type 2 diabetes in association with insulin resistance. Circulation. 2000; 101:1780-1784

17. Monti LD, Barlassina C, Citterio L et al. Endothelial nitric oxide synthase polymorphisms are associated with type 2 diabetes and the insulin resistance syndrome. Diabetes. 2003;52:1270-1275.

18. Myers PR, Webel R, Thondapu V, et al. Restenosis is associated with decreased coronary artery nitric oxide synthase. Int J Cardiol. 1996;55: 183-191.

19. Wu TC, Chen YH, Chen JW, et al. Impaired forearm reactive hyperemia is related to late restenosis after coronary stenting. Am J Cardiol. 2000; 85:1071-1076
20. Ikeda U, Yamamoto K, Maeda Y, et al. Endothelin-1 inhibits nitric oxide synthesis in vascular smooth muscle cells. Hypertension. 1997;29:65-69.

21. Piatti PM, Fragasso G, Monti LD, et al. Acute intravenous L-arginine infusion decreases endothelin-1 levels and improves endothelial function in patients with angina pectoris and normal coronary arteriograms: correlation with asymmetric dimetylarginine levels. Circulation. 2003;107: 429-436.

22. Cooke JP, Oka RK. Does leptin cause vascular disease? Circulation. 2002;106:1904-1905

23. Recchia FA, Vogel TR, Hintze TH. NO metabolites accumulate in erythrocyte in proportion to carbon dioxide and bicarbonate concentration. Am J Physiol Heart Circ Physiol. 2000;279:H852-H856.

24. Yamagishi SI, Edelstein D, Du XL, et al. Leptin induces mitochondrial superoxide production and monocyte chemoattractant protein-1 expression in aortic endothelial cells by increasing fatty acid oxidation via protein kinase A. J Biol Chem. 2001;276:25096-25100.

25. Doehner W, Rauchhaus M, Godsland IF, et al. Insulin resistance in moderate chronic heart failure is related to hyperleptinemia, but not to norepinephrine or TNF-alpha. Int J Cardiol. 2002;83:73-81.

26. Soderberg S, Stegmayr B, Ahlbeck-Glaber C, et al. High leptin levels are associated with stroke. Cerebrovasc Dis. 2003;15:63-69.

27. Versaci F, Gaspardone A, Tomai F, et al. Immunosuppressive therapy for the prevention of restenosis after coronary artery stent implantation (IMPRESS Study). J Am Coll Cardiol. 2002;40:1935-1942.

28. Schillinger M, Exner M, Mlekusch W, et al. Acute-phase response after stent implantation in the carotid artery: association with 6-month in-stent restenosis. Radiology. 2003;227:516-521.

29. Takagi T, Yoshida K, Akasaka T, et al. Hyperinsulinemia during oral glucose tolerance test is associated with increased neointimal tissue proliferation after coronary stent implantation in non diabetic patients: a serial intravascular ultrasound study. J Am Coll Cardiol. 2000;36: 731-738.

30. Iozzo P, Chareonthaitawee P, Dutka D, et al. Independent association of type 2 diabetes and coronary artery disease with myocardial insulin resistance. Diabetes. 2002;51:3020-3024.

31. Kahn SE. The relative contributions of insulin resistance and beta-cell dysfunction to the pathophysiology of type 2 diabetes. Diabetologia. 2003;46:3-19.

32. Bergman RN, Finegood DT, Kanh SE. The evolution of $\beta$-cell dysfunction and insulin resistance in type 2 diabetes. Eur $J$ Clin Invest. 2002;32(suppl 3):35-45.

33. The Decode Study Group. Glucose tolerance and mortality: comparison of WHO and American Diabetes Association diagnostic criteria. Lancet 1999;354:617-621.

34. Norhammar A, Tenerz A, Nilsson G, et al. Glucose metabolism in patients with acute myocardial infarction and no previous diagnosis of diabetes mellitus: a prospective study. Lancet. 2002;359:2140-2144. 